\title{
Hyperketolactia occurrence before or after artificial insemination is associated with a decreased pregnancy per artificial insemination in dairy cows
}

\author{
A. Albaaj, ${ }^{1 *}$ M. Jattiot, ${ }^{2}$ L. Manciaux, ${ }^{2}$ S. Saille, ${ }^{2}$ C. Julien, ${ }^{1}$ G. Foucras, ${ }^{1}$ and D. Raboisson ${ }^{1}$ \\ ${ }^{1}$ Interaction Hôtes Agents Pathogènes, Université de Toulouse, Institut National de Recherche Agronomique, \\ École Nationale Vétérinaire de Toulouse, 31076 Toulouse Cedex 3, France \\ ${ }^{2}$ Bretagne Conseil Elevage Ouest, 1 rue Pierre et Marie Curie, CS 80520, 22195 Plérin Cedex, France
}

\begin{abstract}
The reproductive parameters of dairy cattle have continuously declined worldwide over the last 50 years. Nutritional imbalances are identified as risk factors for this decrease of reproductive performance. The present paper aims to quantify the decrease in the pregnancy per artificial insemination $(\mathrm{P} / \mathrm{AI})$ in the case of high milk ketones before and after AI. A total of 388,731 test-day from the Brittany Milk Recording Program in France from 226,429 cow-lactations were provided for this trial. For each test-day, information about lactation characteristics, date of AI, date of the following calving, and acetone and $\beta$-hydroxybutyrate (BHB) values were included. Ketones were predicted by Fourier transform mid-infrared spectroscopy using MilkoScan Foss analyzers (Foss, Hillerød, Denmark). Many thresholds were evaluated to define cows with hyperketolactia. Hyperketolactia statuses were then categorized into 1 of 4 possible classes according to the milk ketone dynamics for each AI and each threshold of acetone or BHB values (low-low, high-low, low-high, and high-high) within $20 \mathrm{~d}$ before and after AI. Similarly, the dynamics of udder health were characterized by changes in somatic cell counts measured at the same test day as ketone bodies. A logistic regression with a Poisson correction was performed to explain the relationship of $\mathrm{P} /$ AI with milk ketones and somatic cell count dynamics. Predicted acetone and BHB ranged from -0.51 to 4.92 $\mathrm{m} M($ mean $=0.08 \mathrm{~m} M, \mathrm{SD}=0.10 \mathrm{mM})$ and -0.62 to $5.85 \mathrm{~m} M($ mean $=0.07 \mathrm{~m} M, \mathrm{SD}=0.1 \mathrm{~m} M)$, respectively. Hyperketolactia defined by high acetone levels before AI was not associated with decreased P/AI, but high acetone levels after AI were associated with a $>10 \%$ reduction in $\mathrm{P} / \mathrm{AI}$ for all thresholds $>0.10 \mathrm{mM}$.
\end{abstract}

Received February 12, 2019.

Accepted May 15, 2019.

*Corresponding author: ahmad.albaaj@yahoo.com
Hyperketolactia, defined by high BHB values before, after, or before and after AI, was associated with a 6 to $14 \%$ reduction in $\mathrm{P} / \mathrm{AI}$ compared with cows with low BHB values. These associations are lower than those reported in previous trials in which blood ketones were used. High ketones in advanced lactation are likely to be the result of various primary disorders (secondary ketosis). Because the present work demonstrated that this situation is considered a risk factor for deteriorated reproductive performance, we suggest that high ketones in early and advanced lactation should be of interest to farm advisors.

Key words: dairy cow, reproduction, hyperketolactia

\section{INTRODUCTION}

The reproductive performance of dairy cows represents a key parameter of dairy profitability and sustainability. Many factors, including environmental, management, and nutritional factors, affect reproductive performance. Negative energy balance (NEB) is very common in early-lactation cows (Duffield et al., 2009), which leads to fat mobilization characterized by a release of nonesterified fatty acids (NEFA) from fat body reserves and an excessive production of circulating ketone bodies, such as acetone and BHB, after calving (Duffield et al., 1998). Hyperketonemia is defined as an increased concentration of ketones in dairy cow blood after calving. The gold standard for hyperketonemia diagnosis is the measurement of BHB in serum or plasma early postpartum (Duffield et al., 1998). Thus, ketosis has been classified as either clinical ketosis (hyperketonemia with clinical signs) or subclinical ketosis (hyperketonemia without clinical signs). The highest incidence of subclinical ketosis is reported within the first 1 to $3 \mathrm{wk}$ of lactation (Oetzel, 2004; Duffield et al., 2009). The prevalence of hyperketonemia is influenced by a variety of factors. Hyperketonemia rates are higher in farms with long dry periods and inadequate feed management for transition cows (Kaufman et al., 
2016). High-producing cows are more susceptible to subclinical ketosis, as are cows calving during the hot and cold seasons. Moreover, a smaller herd size compared with larger herd size and partially mixed rations compared with total mixed rations are risk factors for ketosis (Berge and Vertenten, 2014). Higher BCS at the end of the dry period dramatically reduces DMI after calving and increases NEB and ketosis occurrence (Rukkwamsuk et al., 1999; Busato et al., 2002; Garro et al., 2014). Two recent meta-analyses highlighted that many outcomes, including an increase in disease prevalence and a decrease in reproduction performance, were associated with hyperketonemia (Raboisson et al., 2014; Abdelli et al., 2017).

Estimations of milk acetone and BHB concentrations are now routinely available in several farms through new algorithms developed using mid-infrared spectroscopy profiles recorded from milk recording programs or regular measurements made by automatic milking systems (Tatone et al., 2017). Ketone body concentrations from blood and milk were shown to correlate positively $(\mathrm{r}=0.66$ to 0.96 ) (Enjalbert et al., 2001). From a practical point of view, detection of ketosis through increased milk ketones (hyperketolactia; HKL) is technically much easier than measuring blood levels. The similarities and differences between these 2 forms of ketosis determination are a topic of intense discussion. First, both definitions disregard the clinical signs and may include both subclinical ketosis (SCK) and clinical ketosis. Second, the threshold to be used for SCK diagnosis remains unclear for milk ketones, whereas a consensus is available for blood. Thresholds of 0.15 $\mathrm{m} M$ for milk acetone and $0.10 \mathrm{~m} M$ for milk BHB have been proposed (de Roos et al., 2007), but another study concluded that the optimal threshold values for HKL were milk acetone $\geq 0.08 \mathrm{~m} M$ and $\mathrm{BHB} \geq 0.20$ $\mathrm{m} M$ (Denis-Robichaud et al., 2014). The prevalence of HKL, defined as milk BHB $\geq 0.15 \mathrm{~m} M$, in cows tested within the first 30 DIM was reported to be $21 \%$ in Canada (Duffield et al., 2009). In Europe, SCK, defined as a keto-test (a milk BHB test strip) $\geq 100 \mu \mathrm{mol} / \mathrm{L}$ in milk, was found to have a prevalence of $39 \%$ (Berge and Vertenten, 2014).

The studies on outcomes associated with SCK or hyperketonemia have mainly been performed with blood ketones; however, large data sets on milk ketones may offer new opportunities to estimate these outcomes. The association between high ketones and reproduction performance is of interest because few studies have focused on this relationship, and some of them fail to highlight any statistical association. This situation may arise from a lack of large data sets by which to identify risk factors of multifactorial outcomes, such as repro- duction performance, because blood sampling limits sample size.

In the present study, we aimed to quantify changes in pregnancy per artificial insemination $(\mathbf{P} / \mathbf{A I})$ related to different thresholds of milk ketone bodies through a large database. We specifically aimed to define the link between $\mathrm{P} / \mathrm{AI}$ and HKL defined by high ketone bodies before and after AI, and to evaluate whether HKL could help to predict AI success.

\section{MATERIALS AND METHODS}

\section{Data and Variables}

Herd records from members of the milk-recording program in the French Brittany region were provided for the period 2013-2016 by Bretagne Conseil Elevage Ouest (BCEL; http://www.bcel-ouest.fr/). In total, 388,731 test-days from 226,429 cow-lactations were retained in this trial. These records included lactation number, calving date, all test-day milk results, and lactation characteristics (length and production) for all lactations. The milk-recording program represented 72 , 72 , and $76 \%$ of the herds, cows, and milk produced for this area, respectively. Data on AI, including identification of dams and sires and dates of AI, were available. For each test-day, data were collected using MySQL software (version 5.0, Oracle Corp., Redwood City, CA). Restrictions were implemented, and only Holstein cows with milk yields (MY) between 4,000 and 12,000 $\mathrm{kg}$ and AI between 45 and 265 DIM (with a mean of 93 d) were included in the study; MY was adjusted to correspond to a reference lactation period of $305 \mathrm{~d}$ (305-d MY).

Each AI was considered a binary trait and defined as successful if it was followed by a calving after a referent pregnancy period. The referent period was defined according to the mean pregnancy period of $289 \mathrm{~d}$ for Holstein cows in France \pm 19 d, as recommended by the French Livestock Institute (http://idele.fr/).

Ketone body measurements in milk were performed monthly during the first 4 mo after calving. Milk concentrations of acetone and BHB were measured in the local official laboratory for milk analysis (MyLab 29270 Carhaix; http://www.labo-mylab.fr/) using a MilkoScan Foss analyzer (Foss, Hillerød, Denmark). These analyzers used Fourier transform (FT) midinfrared (MIR) spectrometry and were subjected to a specific calibration to predict acetone and BHB contents. The prediction equations were established by comparisons with a physico-chemical reference with a continuous flow analyzer (San ++ , Skalar, Breda, the Netherlands) using the procedure described by de Roos 
et al. (2007). The parameterization of each analyzer was regularly monitored to ensure the reliability and repeatability of the results (Guaranteed Samples, Cecalait; https://www.cecalait.fr/). The negative ketone body concentrations obtained from the algorithm applied to the MIR spectrum were kept in databases, and the associated animals were considered to not have HKL. Many thresholds were considered to define positive tests $(0.05,0.1,0.15,0.18,0.2,0.3$, and $0.4 \mathrm{mM}$ for acetone; 0.1, 0.12, 0.15, 0.17, and 0.2 for BHB) and identify cows with HKL based on thresholds proposed in the literature (Heuer et al., 2001; Reist et al., 2003; Denis-Robichaud et al., 2014). The HKL status was then categorized into 1 of 4 possible classes according to either acetone or BHB changes around each AI and for each threshold of acetone or BHB. Cows with a low level both before and after AI were considered the control group (low-low, LL). Cows with a low level before and high level after AI composed the low-high (LH) group, cows with a high level before and low level after AI composed the high-low (HL) group, and cows with a high level both before and after AI composed the high-high (HH) group. This classification was done for all thresholds and each threshold was tested in a separated model.

Udder health around AI was investigated through the SCC values measured on the same test day as ketone bodies. The SCC values were classified as high or low based on a threshold of 200,000 cells $/ \mathrm{mL}$, and 4 classes were created to describe SCC dynamics around AI in the same way as HKL status (LL, LH, HL, and $\mathrm{HH}$ ). The durations between the previous test day and $\mathrm{AI}$ and between $\mathrm{AI}$ and the following test day were restricted to $20 \mathrm{~d}$ (with mean intervals of $11 \mathrm{~d}$ before and $10 \mathrm{~d}$ after AI, respectively) for the main study.

\section{Statistical Analyses}

Data were analyzed using $\mathrm{R}$ (version 2.10.1, 200912-14, The R Foundation for Statistical Computing, Vienna, Austria). A 2-step statistical analysis was performed. First, the best thresholds to define the categorical variables SCC, DIM, and 305-d MY to be included in the final logistic regression (second step) were obtained through generalized additive models (GAM, package gam; https://cran.r-project.org/package=gam). Such models allowed the nature of the relationship between the response and the set of explanatory variables to be determined rather than assuming some form of parametric relationship (Hastie and Tibshirani, 1986). All continuous explanatory variables were then introduced into the model as smooth without a priori assumption, and the P/AI was the outcome variable. The model allowed determination of the most efficient thresholds to be used to define the classes of the explanatory variables SCC, DIM, and 305-d MY. A decreasing linear correlation was observed between AI success and 305-d MY, which was then incorporated into the final model in increasing units of $1,000 \mathrm{~kg}$. Univariable models were created with all of the abovementioned explanatory variables separately, and the multivariable models were built by adding significant variables within the same model one by one to the univariable model.

The final logistic regression with a Poisson correction was then performed using the package nlme. The same step-by-step procedure was used to include explanatory variables as described above for GAM. The final model included the HKL categorical variables defined by different acetone and BHB thresholds and was adjusted by the categorical variable DIM, the continuous variable 305-d MY, and the variable parity. This procedure was applied for the different definitions of HKL. All models (GAM or logistic) included herd as a random variable and were applied either to the first AI following each calving or to all AIs.

For both metabolites tested, a range of test result cutoff points was tested for an association with $\mathrm{P} / \mathrm{AI}$, and their epidemiologic test characteristics (sensitivity and specificity) were calculated. Receiver operator characteristic curves were constructed to determine the optimum threshold among the significant cutoff points.

\section{RESULTS}

A description of the ketone data set used in this study is reported in Table 1 . The mean $\mathrm{P} / \mathrm{AI}$ rate at first AI was $51.6 \%$ for cows from all lactations. The rates were $54.3,50.9,49.1$, and $46.8 \%$ for cows from first, second, third, and greater than third lactations, respectively. The distribution of acetone and BHB concentrations for the first test days and test days before and after the first AI are provided in Table 1. The prevalence of HKL depending on the threshold retained is summarized in Table 2.

Dynamics of SCC, DIM, 305-d MY, and parity were significantly associated with $\mathrm{P} / \mathrm{AI}$ in all models. The coefficients observed were the same regardless of whether the ketone threshold was retained or whether acetone or BHB was used. Increased SCC around AI was significantly associated $(P<0.001)$ with decreased $\mathrm{P} / \mathrm{AI}$. This reduction was more notable when the SCC increase occurred after AI (13\% less likely compared with no increase in SCC for a threshold of 200,000 cells $/ \mathrm{mL}$ ) than before AI ( $6 \%$ less likely) or both before and after AI (9\% less likely). Early ( $<85$ DIM) and late $(>120$ DIM) AI dates were associated with decreased $\mathrm{P} / \mathrm{AI}$. Cows with high MY were less likely to conceive than those with low MY: each 1,000-kg increase in 
305-d MY was associated with a $13 \%$ decrease in $\mathrm{P} /$ AI. Artificial insemination had a greater chance of success in multiparous cows than in primiparous cows. No interaction between the abovementioned variables or with HKL was detected, and the interaction item was thus removed from the final model.

Defined by acetone concentrations before AI (HL group), HKL was significantly $(P<0.05)$ associated with a decrease in $\mathrm{P} / \mathrm{AI}$ for thresholds of 0.3 and 0.4 $\mathrm{m} M$ only (Table 3 ). The prevalence of HKL, however, was particularly low (1.0 to $0.4 \%$ ). The association was weakly positive for low thresholds. Defined by BHB concentration before AI (HL), HKL was significantly $(P<0.01)$ and systematically but weakly associated with a decrease in $\mathrm{P} / \mathrm{AI}$ (Table 4 ), which was 4 to $9 \%$ less likely in the case of high BHB than low BHB, depending on the BHB threshold retained.

Hyperketolactia, defined by an increase in acetone concentrations after AI (LH group), was significantly associated with a decrease in $\mathrm{P} / \mathrm{AI}$. The association was observed regardless of the threshold and was particularly strong for high thresholds. For instance, for a threshold of $0.1 \mathrm{mM}, \mathrm{P} / \mathrm{AI}$ was $10 \%$ less likely for milk acetone $>0.1 \mathrm{~m} M$, which corresponded to an HKL prevalence of $7.3 \%$. An increase in BHB concentration after AI was also significantly associated $(P<0.05)$ with a decrease in $\mathrm{P} / \mathrm{AI}$ (Table 4). The magnitude of the association was of the same order as those observed in individuals with an increased concentration of BHB before AI.

Compared with cows without HKL (LL), cows with HKL both before and after AI (group HH) had a reduced P/AI that was identical to or slightly greater than those of groups LH and HL for BHB and a tendency for a reduced $\mathrm{P} / \mathrm{AI}$ for acetone, with a nonsystematic statistically significant association $(P<0.05)$.

The predictive model failed to identify the best $\mathrm{BHB}$ or acetone value to be used as a threshold. The sensitivity and specificity values were the same for all thresholds of acetone (66 and $48 \%$, respectively) and BHB (69 and $46 \%$, respectively), regardless of the univariate or multivariate model run.

\section{DISCUSSION}

The acetone concentrations reported in the present work are lower than those reported using the same measurement method by de Roos et al. (2007; from

Table 1. Descriptive statistics of DIM and milk ketone concentrations on the first test day and test days before and after the first AI

\begin{tabular}{|c|c|c|c|}
\hline Item & First test day & $\begin{array}{l}\text { Test day before } \\
\text { first AI }\end{array}$ & $\begin{array}{l}\text { Test day after } \\
\text { first AI }\end{array}$ \\
\hline \multicolumn{4}{|l|}{ DIM } \\
\hline Minimum & 7 & 7 & 55 \\
\hline Median & 27 & 78 & 94 \\
\hline Mean & 29 & 75 & 93 \\
\hline Maximum & 86 & 118 & 119 \\
\hline \multicolumn{4}{|l|}{ Acetone $(\mathrm{m} M)$} \\
\hline Minimum & -0.51 & -0.51 & -0.34 \\
\hline 1 st and 5 th percentiles & -0.061 and -0.02 & -0.06 and -0.03 & -0.06 and -0.03 \\
\hline 1st quartile & 0.02 & 0.01 & 0.01 \\
\hline Median & 0.07 & 0.05 & 0.05 \\
\hline Mean & 0.09 & 0.06 & 0.05 \\
\hline 1st lactation & 0.09 & 0.06 & 0.05 \\
\hline 2nd lactation & 0.08 & 0.06 & 0.05 \\
\hline 3rd lactation & 0.09 & 0.06 & 0.04 \\
\hline$>3$ rd lactation & 0.10 & 0.06 & 0.04 \\
\hline 3rd quartile & 0.12 & 0.09 & 0.08 \\
\hline 95th and 99th percentiles & 0.27 and 0.49 & 0.15 and 0.25 & 0.14 and 0.19 \\
\hline Maximum & 3.98 & 3.98 & 1.12 \\
\hline \multicolumn{4}{|l|}{$\mathrm{BHB}(\mathrm{m} M)$} \\
\hline Minimum & -0.42 & -0.42 & -0.30 \\
\hline 1st and 5 th percentiles & -0.07 and -0.04 & -0.07 and -0.04 & -0.07 and -0.04 \\
\hline 1st quartile & 0.00 & 0.00 & 0.00 \\
\hline Median & 0.05 & 0.04 & 0.04 \\
\hline Mean & 0.07 & 0.05 & 0.05 \\
\hline 1st lactation & 0.05 & 0.04 & 0.04 \\
\hline 2nd lactation & 0.07 & 0.06 & 0.05 \\
\hline 3rd lactation & 0.08 & 0.06 & 0.05 \\
\hline$>3$ rd lactation & 0.08 & 0.06 & 0.05 \\
\hline 3rd quartile & 0.10 & 0.08 & 0.08 \\
\hline 95th and 99th percentiles & 0.24 and 0.44 & 0.17 and 0.28 & 0.15 and 0.24 \\
\hline Maximum & 3.81 & 2.30 & 1.74 \\
\hline
\end{tabular}


-0.02 to $3.96 \mathrm{mM}$ with an average of $0.15 \mathrm{mM}$ ) and by Denis-Robichaud et al. (2014; from -0.03 to 2.63 with an average of $0.10 \mathrm{mM}$ ). Concentrations of BHB were similar to those from de Roos et al. (2007; from -0.02 to $0.84 \mathrm{~m} M$ with an average of $0.08 \mathrm{~m} M$ ) but lower than those of Denis-Robichaud et al. (2014; from -0.03 to $1.09 \mathrm{~m} M$ with an average of $0.18 \mathrm{~m}$ ). No difference for acetone values was observed among cows of different parity, whereas BHB values increased with increased parity (Table 1).

Depending on the threshold of milk acetone or BHB, the prevalence of HKL in the present study varied from 0.1 to $57.5 \%$ (Table 2) and was, on average, lower than values reported in the literature. This might result from the extended interval between calving and test days in our study compared with those mentioned in the previous studies, which may limit the comparison. The prevalence of HKL was $1.6 \%$ based on a milk acetone concentration of $0.4 \mathrm{~m} M$. For the same threshold and the same period of diagnosis, (Andersson and Emanuelson, 1985) reported a prevalence of $4.7 \%$. The prevalence of HKL was $24.6 \%$ based on a milk BHB concentration of $0.10 \mathrm{~m} M$. This is slightly lower than the $29 \%$ prevalence reported in Hungarian herds (Hejel et al., 2018). The BHB threshold of $0.15 \mathrm{~m} M$ for the first test day led to an HKL prevalence of $13.1 \%$, lower than the $21 \%$ prevalence reported in Canadian dairy herds (Tatone et al., 2017). However, all BHB measurements were performed in the last trial within the first $30 \mathrm{~d}$ after calving. The peak prevalence was reported between 5 and 11 DIM with a steady subsequent decline, reaching $16 \%$ for cattle tested at 27 and 30 DIM. In the present trial, the mean interval between calving and the first test day was $29 \mathrm{~d}$, which may have contributed to the difference in the prevalence rates observed (24.6 vs. $29 \%$ ).

The negative association between HKL and reproductive performance is consistent and based on pathophysiological and epidemiological evidence (Raboisson et al., 2014; Abdelli et al., 2017), despite some controversial epidemiological results (lack of statistically significant association in some studies). In the present work, HKL before AI, defined on the basis of high acetone values, was not associated with decreased $\mathrm{P} / \mathrm{AI}$, but $\mathrm{HKL}$ after AI was associated with a $>10 \%$ lower $\mathrm{P} / \mathrm{AI}$ for all thresholds $>0.10 \mathrm{~m} M$ of acetone. Hyperketolactia defined by BHB levels was associated with a 6 to $14 \%$ lower $\mathrm{P} / \mathrm{AI}$ for high $\mathrm{BHB}$ levels before, after, or before and after AI, compared with low BHB levels (Table $3)$. These associations are lower than those reported in previous trials. The results of 2 meta-analyses (Raboisson et al., 2014; Abdelli et al., 2017) showed that the pregnancy rate at first AI was reduced by $38 \%$ in cows with elevated blood ketones compared with healthy 


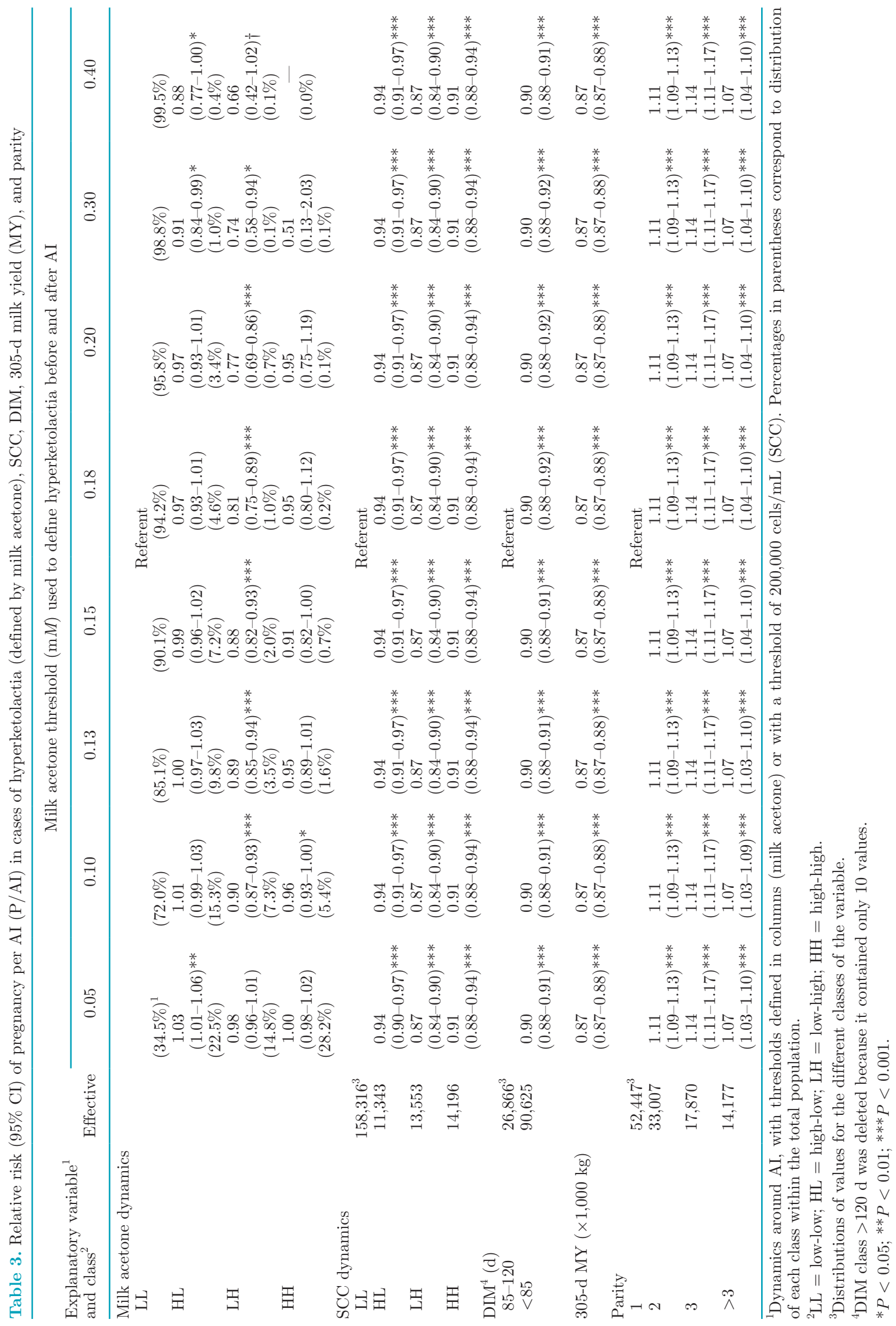


HYPERKETOLACTIAAND FERTILITY IN DAIRY COWS

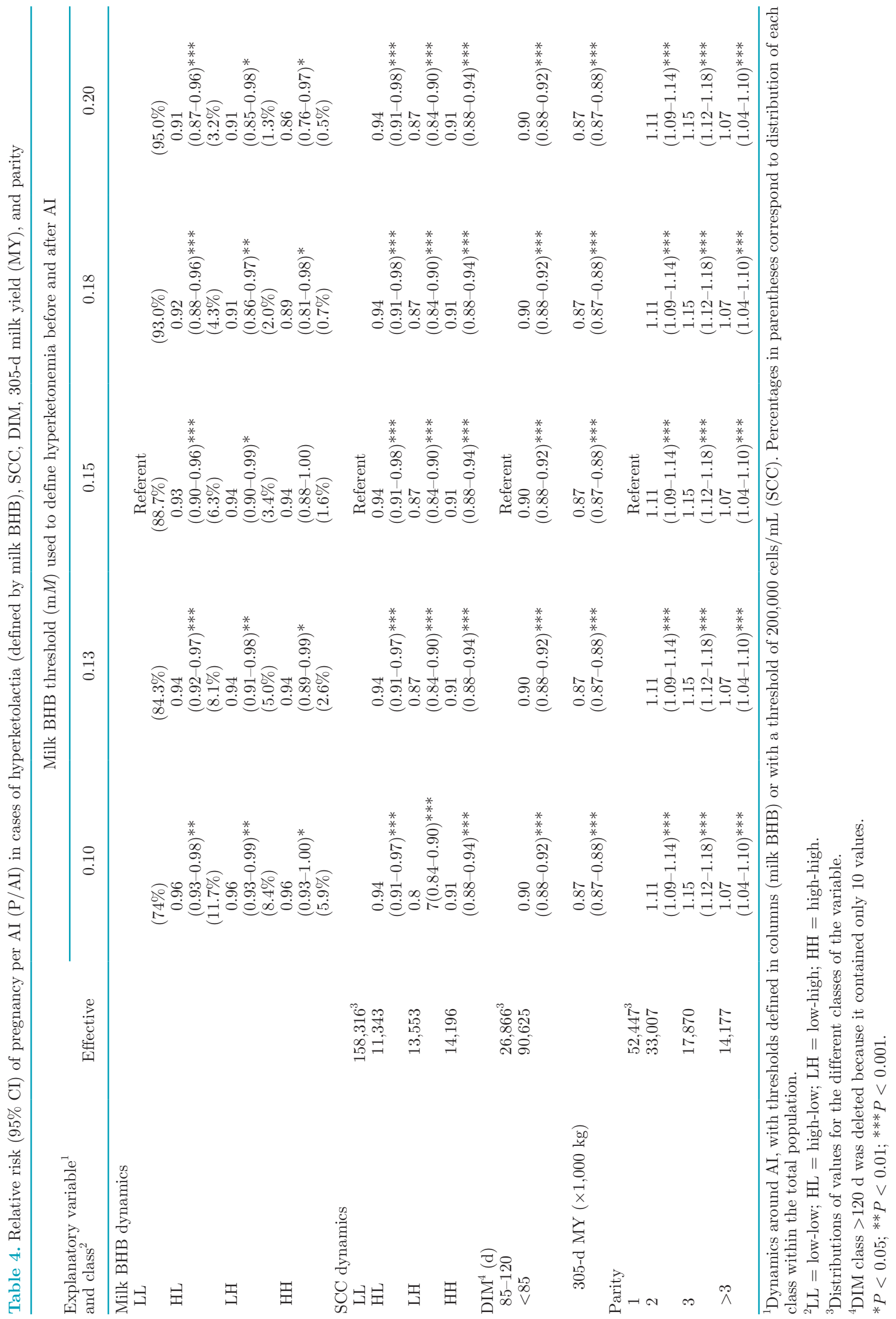


cows [relative risk $(95 \% \mathrm{CI})=0.62(0.41-0.93)]$. This might be explained by the fact that this association is time dependent; cows first diagnosed with SCK between 3 and 7 DIM were $30 \%$ less likely [odds ratio $(95 \%$ CI $)=0.7(0.6-0.8)]$ to conceive at first service than cows first testing positive between 8 and 16 DIM (McArt et al., 2012).

However, previously published models did not always include covariables, and the coefficient value of the subclinical ketosis variable is strongly influenced by the model's covariables (Raboisson et al., 2014). For instance, the models presented in this trial showed a stronger association between HKL and P/AI when they were not adjusted by the covariable milk yield (details not reported). The lack of association between high acetone before $\mathrm{AI}$ and $\mathrm{P} / \mathrm{AI}$ remains incompletely understood, even though it might be explained by low statistical power due to the small number of cows in this category.

Surprisingly, the sensitivity and specificity calculated in the predictive model (66 and $48 \%$, respectively) were not dependent on the retained BHB or acetone thresholds. This is not in agreement with previous studies, in which the majority of the trials managed to identify an optimum threshold for maximizing sensitivity and specificity. First, the use of milk rather than blood indicators may contribute to this difference. The MIR spectrum to evaluate milk ketones is associated with a sensitivity and specificity, respectively, of 66 and 70 to $95 \%$ for BHB and 60 and $70 \%$ for acetone, according to published references (de Roos et al., 2007; van Knegsel et al., 2010). A previous study reported that the coefficient of variation for repeatability of the Fourier transform infrared milk BHB test is $4.56 \%$ (Tatone et al., 2017). This level of performance may contribute to the low sensitivity and specificity of the present results. However, the present models estimate a probability of success that cannot be validated at the cow level because the result of AI is binary (pregnant or not) and is not a probability, which might limit the relevance of the predictive goal. A similar result was reported recently where predicting pregnancy had a mediocre quality using models that include parity, stage of lactation, milk production, breed, season, fat-to-protein ratio, and BCS as variables (Rutten et al., 2016). Second, the duration of high ketone exposure is probably an important confounding factor in the analysis between high ketone concentrations and health or production outcomes. It may contribute to the low performance of P/AI prediction observed here. Together, these results suggest that the limited sensitivity and specificity of milk ketones as a test to predict $\mathrm{P} / \mathrm{AI}$ at the cow level is limited in practice. Further research is needed to evaluate how this may predict low $\mathrm{P} / \mathrm{AI}$ at the herd level.
Despite these limitations, the present results showed that the association was more remarkable when HKL occurred after AI than before AI, which might limit the accuracy of pregnancy prediction based on characteristics that must be available before AI. The significant association between HKL after AI and P/ AI has not been reported before. The strength of this association is particularly important for acetone even though this indicator is only partially associated with $\mathrm{P} / \mathrm{AI}$ when measured before AI. However, the potential physiological mechanisms to explain this association remain unknown. Because SCC dynamics around AI are accounted for in the present study, mastitis cannot be considered a cofounding factor underlying the association observed between HKL after AI and the decrease in $\mathrm{P} / \mathrm{AI}$. Mastitis and increases in SCC are known to decrease the odds of $\mathrm{P} / \mathrm{AI}$ when occurring after AI (Albaaj et al., 2017).

Unfortunately, the duration of high ketone exposure is poorly studied and understood. The median time from the first positive test (blood BHB $\geq 1.2 \mathrm{mM}$ ) until $\mathrm{BHB}<1.2 \mathrm{~m} M$ was reported to be $5 \mathrm{~d}$ when the sampling frequency was 6 samples and tests were done from 3 to 16 DIM (McArt et al., 2012). Cows diagnosed with SCK at least once within the first $2 \mathrm{wk}$ were $17 \%$ less likely (but $P>0.05$ ) to be pregnant after the first AI, whereas cows that remained above the SCK thresholds during the first 2 wk were $53 \%$ less likely [odds ratio $(95 \% \mathrm{CI})=0.47(0.29-0.77)]$ to conceive after the first AI (Walsh et al., 2007). In the present study, elevated concentrations of ketone bodies only after AI were associated with an equal or lesser chance of P/AI compared with a long period of HKL (before and after AI). Thus, the associations observed for HKL after AI cannot be confused with long-term HKL because the models have been adjusted to this situation. The present study failed to identify a precise range of ketone concentrations because only one test day per month was available on average. The objective of the trial was not to redefine the diagnostic window of HKL, but the results observed for the period after AI (i.e., in advanced lactation) suggest that focusing on this period could resolve the effect of problematic HKL. High ketones in advanced lactation are likely to be the result of various primary disorders (secondary ketosis).

Although the underlying mechanisms related to the association between ketosis or HKL and reproductive performance have been extensively reviewed, the weight and importance of some of the mechanisms involved remain unclear. This could be due to the complex interaction between the different mechanisms related to NEB, which makes it difficult to measure the effects attributed to changes in ketone concentrations. During the peripartum period, plasma concentrations of NEFA 
and BHB and the hepatic accumulation of triglycerides were higher for cows in which the first postpartum dominant follicle failed to ovulate compared with cows that had ovulatory follicles (Marr et al., 2002). Additionally, metabolic changes associated with ketosis after calving alter the composition of follicular fluid, especially for BHB, as blood and follicular fluid BHB are correlated $(\mathrm{r}=1.00, P<0.05)$ up to $46 \mathrm{~d}$ postpartum (Leroy et al., 2004). Thus, a toxic effect of high BHB on oocyte maturation is a possible explanation because a direct toxic effect of high NEFA in the same phase has been demonstrated (Leroy et al., 2006). Reproductive performance can also be impaired due to uterine disease and delayed luteal activity, which in turn are associated with elevated concentrations of NEFA and BHB (Hammon and Goff, 2006; Wathes et al., 2007).

\section{CONCLUSIONS}

The present work confirmed the link between high ketones in dairy cows and $\mathrm{P} / \mathrm{AI}$ and highlighted the association between HKL after AI and P/AI. High milk $\mathrm{BHB}$ values were associated with a reduced chance of $\mathrm{P} / \mathrm{AI}$ compared with low values, regardless of whether a BHB increase was observed before $\mathrm{AI}$, after $\mathrm{AI}$, or before and after AI. High acetone after AI was associated with a significantly reduced chance of $\mathrm{P} / \mathrm{AI}$ for all thresholds $>0.10 \mathrm{~m} M$. Acetone levels before AI and P/ AI were not associated. Our results suggest that high ketones in advanced lactation should be considered a risk factor for deteriorated reproductive performance.

\section{ACKNOWLEDGMENTS}

This work was supported by grants from the RUMINFLAME project, as part of the INRA MetaProgramme Gestion Intégrée de la Santé Animale (Institut National de Recherche Agronomique, Paris, France).

\section{REFERENCES}

Abdelli, A., D. Raboisson, R. Kaidi, B. Ibrahim, A. Kalem, and M. Iguer-Ouada. 2017. Elevated non-esterified fatty acid and $\beta$-hydroxybutyrate in transition dairy cows and their association with reproductive performance and disorders: A meta-analysis. Theriogenology 93:99-104.

Albaaj, A., G. Foucras, and D. Raboisson. 2017. High somatic cell counts and changes in milk fat and protein contents around insemination are negatively associated with conception in dairy cows. Theriogenology 88:18-27.

Andersson, L., and U. Emanuelson. 1985. An epidemiological study of hyperketonaemia in Swedish dairy cows; Determinants and the relation to fertility. Prev. Vet. Med. 3:449-462.

Berge, A. C., and G. Vertenten. 2014. A field study to determine the prevalence, dairy herd management systems, and fresh cow clinical conditions associated with ketosis in western European dairy herds. J. Dairy Sci. 97:2145-2154.
Busato, A., D. Faissler, U. Küpfer, and J. W. Blum. 2002. Body condition scores in dairy cows: Associations with metabolic and endocrine changes in healthy dairy cows. J. Vet. Med. Ser. A 49:455460.

de Roos, A. P. W., H. J. C. M. van den Bijgaart, J. Hørlyk, and G. de Jong. 2007. Screening for subclinical ketosis in dairy cattle by Fourier transform infrared spectrometry. J. Dairy Sci. 90:1761-1766.

Denis-Robichaud, J., J. Dubuc, D. Lefebvre, and L. DesCoteaux. 2014. Accuracy of milk ketone bodies from flow-injection analysis for the diagnosis of hyperketonemia in dairy cows. J. Dairy Sci. 97:3364-3370.

Duffield, T. F., D. Sandals, K. E. Leslie, K. Lissemore, B. W. McBride, J. H. Lumsden, P. Dick, and R. Bagg. 1998. Efficacy of monensin for the prevention of subclinical ketosis in lactating dairy cows. J. Dairy Sci. 81:2866-2873.

Duffield, T. F. F., K. D. D. Lissemore, B. W. W. McBride, and K. E. E. Leslie. 2009. Impact of hyperketonemia in early lactation dairy cows on health and production. J. Dairy Sci. 92:571-580.

Enjalbert, F., M. C. Nicot, C. Bayourthe, and R. Moncoulon. 2001. Ketone bodies in milk and blood of dairy cows: relationship between concentrations and utilization for detection of subclinical ketosis. J. Dairy Sci. 84:583-589.

Garro, C. J., L. Mian, and M. Cobos Roldan. 2014. Subclinical ketosis in dairy cows: Prevalence and risk factors in grazing production system. J. Anim. Physiol. Anim. Nutr. (Berl.) 98:838-844.

Hammon, D. S., and J. P. Goff. 2006. Immune function and energy status in Holstein cows with uterine infections. Pages 29-36 in Proc. of the Mid-South Ruminant Nutr. Conf. 2006.

Hastie, T., and R. Tibshirani. 1986. Generalized additive models. Stat. Sci. 1:297-310.

Hejel, P., G. Zechner, C. Csorba, and L. Könyves. 2018. Survey of ketolactia, determining the main predisposing management factors and consequences in Hungarian dairy herds by using a cow-side milk test. Vet. Rec. Open 5:e000253.

Heuer, C., H. J. Luinge, E. T. G. Lutz, Y. H. Schukken, J. H. van der Maas, H. Wilmink, and J. P. T. M. Noordhuizen. 2001. Determination of acetone in cow milk by Fourier transform infrared spectroscopy for the detection of subclinical ketosis. J. Dairy Sci. $84: 575-582$.

Kaufman, E. I., S. J. LeBlanc, B. W. McBride, T. F. Duffield, and T. J. DeVries. 2016. Short communication: Association of lying behavior and subclinical ketosis in transition dairy cows. J. Dairy Sci. 99:7473-7480.

Leroy, J. L. M. R., T. Vanholder, J. R. Delanghe, G. Opsomer, A. Van Soom, P. E. J. Bols, J. Dewulf, and A. De Kruif. 2004. Metabolic changes in follicular fluid of the dominant follicle in high-yielding dairy cows early post partum. Theriogenology 62:1131-1143.

Leroy, J. L. M. R., T. Vanholder, G. Opsomer, A. Van Soom, and A. De Kruif. 2006. The in vitro development of bovine oocytes after maturation in glucose and $\beta$-hydroxybutyrate concentrations associated with negative energy balance in dairy cows. Reprod. Domest. Anim. 41:119-123.

Marr, A. L., M. S. Piepenbrink, T. R. Overton, M. C. Lucy, and W. R. Butler. 2002. The somatotrophic axis and lipid metabolism in transition dairy cows in relation to timing of first postpartum ovulation. J. Dairy Sci. 85 (Suppl. 1):66. (Abstr.)

McArt, J. A. A., D. V. Nydam, and G. R. Oetzel. 2012. Epidemiology of subclinical ketosis in early lactation dairy cattle. J. Dairy Sci. 95:5056-5066.

Oetzel, G. R. 2004. Monitoring and testing dairy herds for metabolic disease. Vet. Clin. North Am. Food Anim. Pract. 20:651-674.

Raboisson, D., M. Mounié, and E. Maigné. 2014. Diseases, reproductive performance, and changes in milk production associated with subclinical ketosis in dairy cows: A meta-analysis and review. J. Dairy Sci. 97:7547-7563.

Reist, M., D. K. Erdin, D. von Euw, K. M. Tschümperlin, H. Leuenberger, H. M. Hammon, N. Künzi, and J. W. Blum. 2003. Use of threshold serum and milk ketone concentrations to identify risk for ketosis and endometritis in high-yielding dairy cows. Am. J. Vet. Res. 64:188-194. 
Rukkwamsuk, T., T. A. Kruip, and T. Wensing. 1999. Relationship between overfeeding and overconditioning in the dry period and the problems of high producing dairy cows during the postparturient period. Vet. Q. 21:71-77.

Rutten, C. J., W. Steeneveld, J. C. M. Vernooij, K. Huijps, M. Nielen, and $\mathrm{H}$. Hogeveen. 2016. A prognostic model to predict the success of artificial insemination in dairy cows based on readily available data. J. Dairy Sci. 99:6764-6779.

Tatone, E. H., T. F. Duffield, S. J. LeBlanc, T. J. DeVries, and J. L. Gordon. 2017. Investigating the within-herd prevalence and risk factors for ketosis in dairy cattle in Ontario as diagnosed by the test-day concentration of $\beta$-hydroxybutyrate in milk. J. Dairy Sci. 100:1308-1318. van Knegsel, A. T. M., S. G. A. van der Drift, M. Horneman, A. P. W de Roos, B. Kemp, and E. A. M. Graat. 2010. Short communication: Ketone body concentration in milk determined by Fourier transform infrared spectroscopy: Value for the detection of hyperketonemia in dairy cows. J. Dairy Sci. 93:3065-3069.

Walsh, R. B., J. S. Walton, D. F. Kelton, S. J. LeBlanc, K. E. Leslie, and T. F. Duffield. 2007. The effect of subclinical ketosis in early lactation on reproductive performance of postpartum dairy cows J. Dairy Sci. 90:2788-2796.

Wathes, D. C., N. Bourne, Z. Cheng, G. E. Mann, V. J. Taylor, and M. P. Coffey. 2007. Multiple correlation analyses of metabolic and endocrine profiles with fertility in primiparous and multiparous cows. J. Dairy Sci. 90:1310-1325. 